\title{
COMPETENCIES OF PHYSICAL EDUCATION TEACHERS IN CONDUCTING ONLINE EDUCATION
}

\author{
Veselina Ivanova ${ }^{1}$, Eleonora Mileva ${ }^{2}$
}

\begin{abstract}
The state of emergency, as a result of the COVID-19 pandemic, has completely changed the education system in Bulgaria, including the training of physical education and sports in Bulgarian schools. Physical education and sports training have been transformed into distance and online education and training. The aim of the research was to study the competencies of PE teachers in the country for the implementation of online teaching. The subject of the study was a total of 138 teachers, of whom 100 (72.5\%) were female and 38 (27.5\%) were male. The teachers were aged from 24 to 68 years old, with different pedagogical experience and were representatives of all regions of the country. A specially developed international questionnaire with closed questions was applied. Alternative analysis and chi-square Pearson's test $\left(\times^{2}\right)$ were used to analyze the results. The results show that the sampled teachers evaluated the current use of online education in physical education and sport as relatively good $(47.1 \%)$. At the same time, the acquired results show that the educational activity of sports pedagogues during the pandemic has reduced their motivation for professional activity (43.5\%). Teachers have rated as very good (29.7\%) and good (45.7\%) their competencies for using online technologies to conduct physical education and sports classes. The majority of them $-79 \%$, actively applied the new technologies in the training process. No differences were found in the answers of the respondents to any of the questions on the criteria of gender, age and pedagogical experience.
\end{abstract}

UDC Classification: 37.09, DOI: https://doi.org/10.12955/pss.v2.217

Keywords: PE teachers, online teaching, competencies, technology, pandemic

\section{Introduction}

The state of emergency as a result of the COVID-19 pandemic has tested the normal life of people around the world. It has completely changed the educational system in Bulgaria, including the teaching of physical education and training of sports (Hristakieva, 2020). Most of the lecturers started using distance learning at the beginning of the state of emergency (Getova, Mileva \& Angelova-Igova, 2020; Savcheva \& Domuschieva-Rogleva, 2020). It was important for teachers to create the capability to integrate organizational communication, professional collaboration, and effective practice and development (Tejedor et al., 2020).

Physical education and sports training have been transformed into distance and online education and training. The physical activity of students from all educational levels was significantly reduced. This point of view was reflected in different studies on the problem (Gobbi et al., 2020; Galle et al., 2020). At the same time physical activity was adapted to the conditions of the lockdown situation (Sivevska \& Popeska, 2020).

On March 13, 2020, schools in Bulgaria were moved to distance learning as a result of the state of emergency in the country. Online teaching in all subjects, including physical education and sports was organized by the Ministry of Education and Science. All teachers in Bulgaria were provided with access to the Microsoft Teams platform with all its applications. Teachers could use free teaching materials of various kinds on a special Bulgarian platform (Naydenova \& Chernev, 2020).

Many teachers of physical education (PE) and sports use other online platforms and resources to conduct sports training such as Google Classroom, Viber, Messenger, Zoom, Skype, Schkolo, Facebook groups, and other electronic platforms of the school, through which they communicate with their students (https://e-learn.mon.bg/public/study-resources). Feedback tests, e-lessons, exercise videos, training films were also included.

At the beginning of the COVID-19 pandemic in March and April 2020, distance learning was quite chaotic, but with the accumulation of experience PE teachers were able to organize their training successfully. The teachers independently developed part of the teaching material for the teaching of physical education, showing creativity in presentations, videos, educational films, searching for materials on social media, etc.

The training in PE was mainly aimed at getting acquainted with the studied sports, with the presentation of the basic motor exercises and techniques of the different sports discipline, as well as with the history and development of the sport (Sabev, 2021). The teachers demonstrated very good

\footnotetext{
${ }^{1}$ Veselina Ivanova, Faculty of Education, Trakia University, Stara Zagora, Bulgaria, v_g_chipeva@abv.bg

2 Eleonora Mileva, National Sports Academy “Vassil Levski”, Sofia, Bulgaria, emileva2002@gmail.com
} 
mastery of information and communication technologies and innovations in the course of teaching PE. The most difficult moment during PE education was the implementation of effective feedback with the students and the impossibility for real exercise and sports.

\section{Methodology}

The aim of the research was to study the competencies of PE teachers in Bulgaria for the implementation of online teaching during the COVID-19 pandemic.

The subject of the research was a total of 138 teachers, of whom $100(72.5 \%)$ were female and $38(27.5 \%)$ were male. The teachers were aged from 23 to 68 years old, with different pedagogical experience and were representatives of all regions of the country. The most numerous was the group of middle-aged teachers between 31 and 50 years old (56.5\%). In second place were teachers over 50 (32.6\%) and the smallest was the group of young teachers represented by those up to 30 years old $(10.9 \%)$. Regarding work experience, the largest group were the teachers with the longest experience over 20 years (42\%), followed by teachers with experience of 6 to 20 years (33.3\%). Sports pedagogues with experience of up to 5 years comprised a quarter of the respondents (24.6\%). It should be noted that $92.8 \%$ of the teachers work in public schools. $41.3 \%$ of the teachers that participated in this research work solely in primary schools and $29.7 \%$ of them work only in secondary schools. $29 \%$ of the PE teachers in our study have classes in both educational levels.

The data about the size of the cities where PE teachers work also present a special interest. The largest group of teachers are from the capital Sofia $-30.5 \%$. The second largest group includes pedagogues from the big cities of the country $-26.8 \%$, followed by PE teachers from the middle-sized cities $21.7 \%$ and the last group are PE teachers from small towns and villages $-21 \%$.

A specially developed international questionnaire with closed questions was applied in the research. Alternative analysis and chi-square Pearson's test $\left(\times^{2}\right)$ were used to analyze the results.

\section{Results and Discussion}

Analyzing the results, we can observe a clear predominance of positive evaluations of the current online training in physical education over negative ones - $48.5 \%$ of teachers stated it was "very good" and "good" (Figure 1). At the same time, $30 \%$ of teachers rated it at an average level. There are also respondents who said that the current online training in physical education was "bad" and "very bad" $21.5 \%$.

Most probably, the difficulties that accompanied the implementation of online learning at school were not insignificant. It should also be taken into account that teachers were working entirely in an online environment for the first time, which required some prior preparation and adaptation to the conditions and the educational environment.

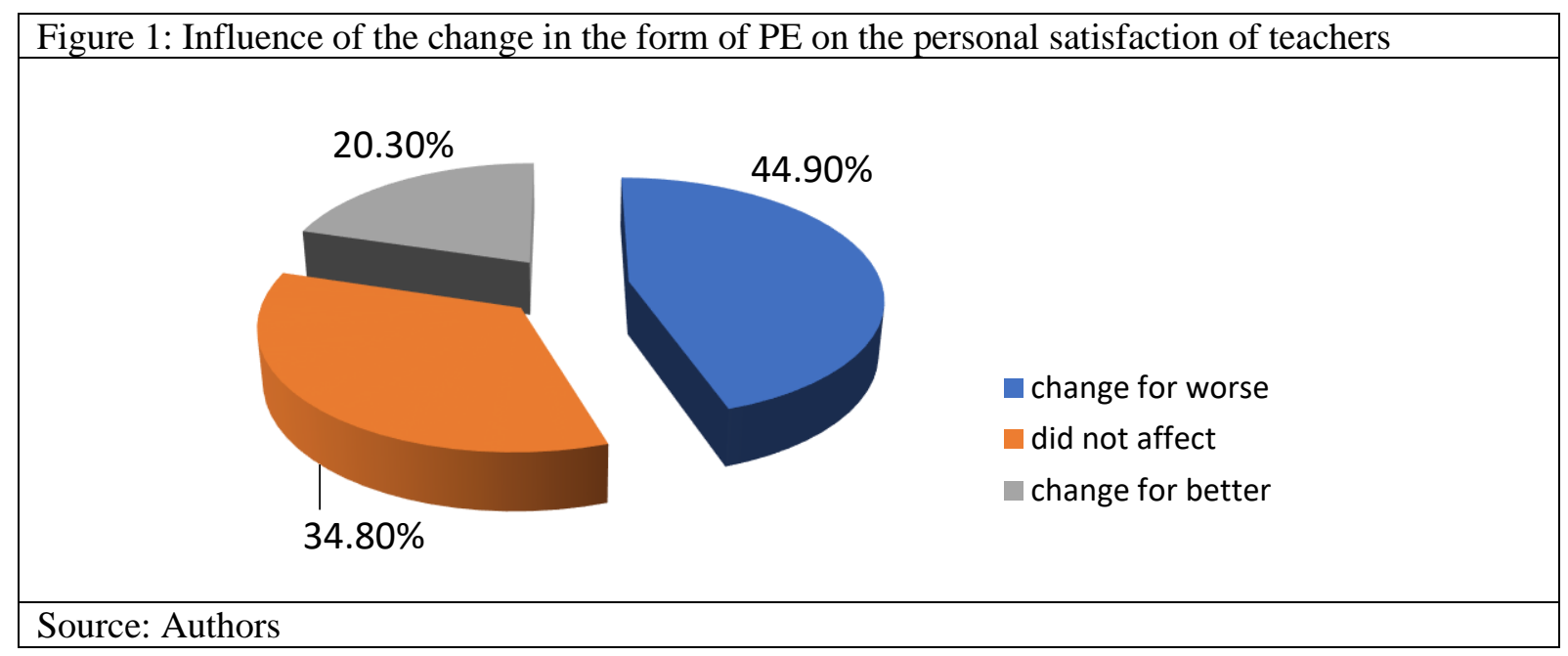

On the question of whether the change in the form and manner of physical education teaching during the pandemic affected the teachers' personal satisfaction and fulfillment of the profession, the biggest group responded that the change was for the worse $-44.9 \%$ (Figure 1). Another significant proportion of teachers stated that online PE training did not affect their personal satisfaction with the profession $34.8 \%$. 
These results also correlate with the reduced motivation of teachers to perform their professional duties during online training as a result of the pandemic $-43.5 \%$. Only $26.8 \%$ found increased motivation for work related to online learning (Figure 2).

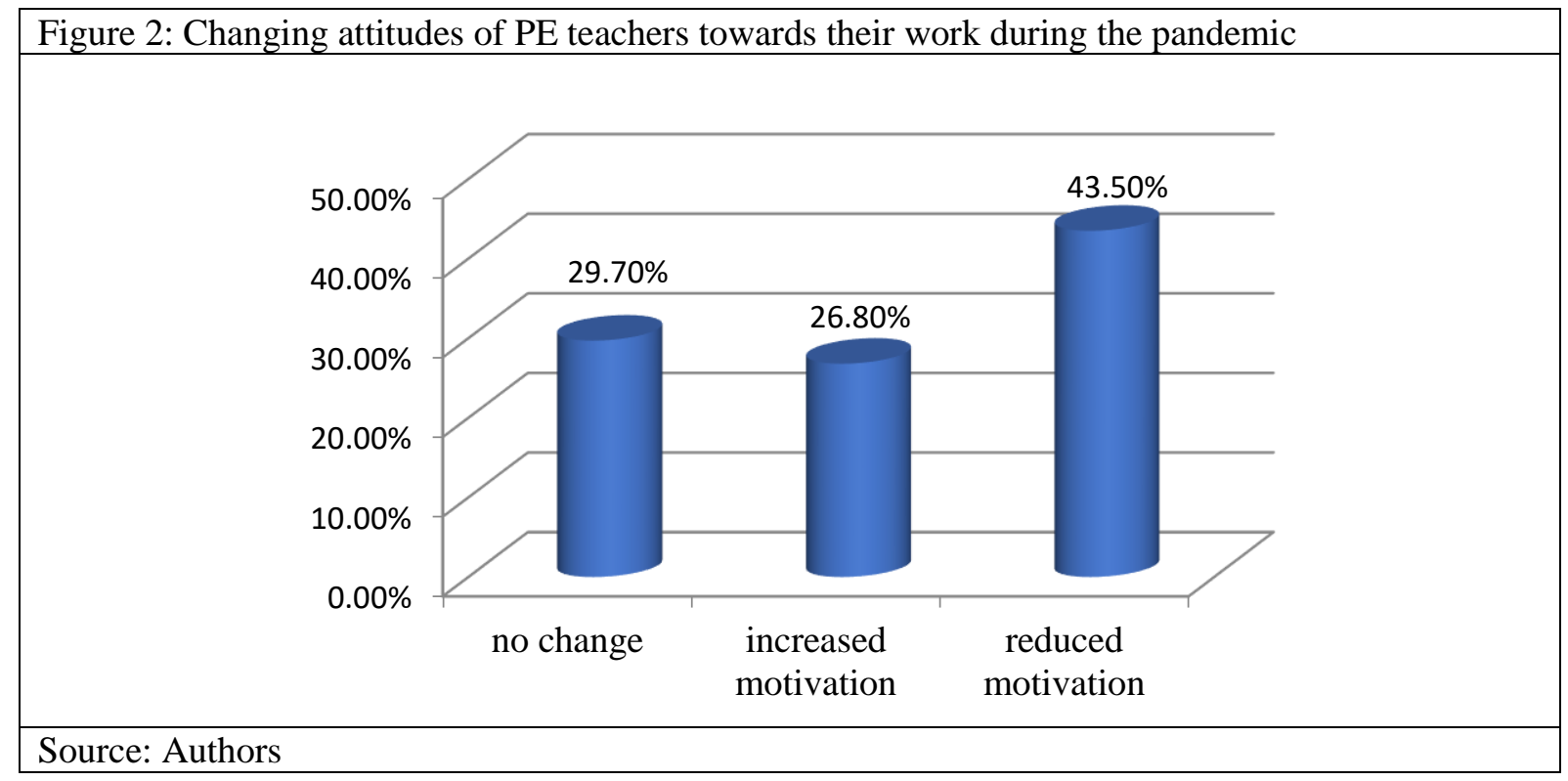

It should be emphasized that physical education is the only subject at school which is connected with active motor activity (Ivanova \& Mileva, 2019). Therefore, conducting physical education classes online is not very appropriate. The online platform cannot provide the necessary sport environment for the students, it does not contribute to the development of their physical qualities and successful sports activities.

When asked if they had used technology in physical education training before the COVID-19 pandemic, $52.9 \%$ of respondents answered positively. This is probably a result of the aspiration of educators to the introduction of innovative approaches in teaching and the use of new technologies. On the other hand, Bulgarian teachers are constantly involved in various professional courses and pedagogical trainings to improve their qualifications. This is also imposed by Regulation № 15 (from 22 July 2019) for the status and professional education development of teachers, principals and other pedagogical specialists, as well as, by the adopted National strategy for development of the pedagogical staff in Bulgaria (2014).

Teachers have rated as very good $(29.7 \%)$ and good (45.7\%) their competencies for using online technologies to conduct physical education and sports classes (Figure 3). Consequently, they have gradually been overcoming the new educational challenges posed by the pandemic. The application of new technologies is considered as an essential part of the professional pedagogical competence, without which it is impossible to carry out effective training in the Internet environment.

\begin{tabular}{|l|l|l|l|l|}
\hline Figure 3: Evaluation of teachers' competencies for online education in PE \\
\hline Sery good
\end{tabular}


It is logical that some of the respondents have assessed their technological skills for conducting online physical education training at an average level - 23.2\%.

It is a very positive fact that the majority of PE teachers - 79\%, actively apply the new technologies new programs, online products and applications in physical education teaching, from the beginning of the pandemic.

It is worth mentioning that physical education teachers used different forms and ways to acquire the necessary knowledge and skills to work with new online applications and learning platforms.

First, the teachers pointed out that they acquired knowledge and skills on the new technologies independently, using instructions on the Internet - 60.9\% (Table 1). The share of pedagogues who gained practical experience with the new technologies by trial and error was high - 53.6\%.

\begin{tabular}{|c|c|c|}
\hline No. & Forms & $\%$ \\
\hline 1 & Independently, via instructions on the Internet & 60.9 \\
\hline 2 & By trial and error & $\mathbf{5 3 . 6}$ \\
\hline 3 & From a course organized at the school & 27.5 \\
\hline 4 & Through materials uploaded by the school & 22.5 \\
\hline 5 & Through education by colleagues and students & 23.9 \\
\hline
\end{tabular}

In fact, the share of respondents who had attended specialized educational courses, organized by the schools where they work to learn how to use new technologies, was not insignificant $-27.5 \%$. The percentage of teachers who had acquired knowledge about online technologies through materials uploaded to the school website was also similar - $22.5 \%$. It is interesting to note that some of the respondents relied on training from their colleagues and students $-23.9 \%$.

From the acquired results, it is clear that sports educators rely mainly on their personal initiative and motivation in the process of gaining and developing specific online skills and competencies.

After the applied Pearson Chi Square Tests $\left(x^{2}\right)$, at $p \leq 0.05$, no differences were found in the answers of the respondents to any of the posed questions, on the criteria of gender, age and length of service. This means that PE teachers were united in their attitudes and preferences for conducting online PE education in the Bulgarian educational system and adequately assessed their competencies in this direction.

\section{Conclusions}

The presented research is one of the first in the country in terms of online physical education teaching. It can be summarized that this type of training is progressing at a good level, although it has been accompanied by some difficulties for the teachers.

In general, there is a reduced motivation for work in an online environment by physical education teachers. At the same time, sports pedagogues have significantly improved their skills in working with new technologies during the pandemic. There are various forms and sources for acquiring new knowledge and competencies.

The study will serve as a basis for future research on the problem of online physical education teaching in Bulgarian schools. Comparative studies on this type of training in different European countries could be very useful in sharing information and experience.

\section{References}

Gallè, F.; Sabella, E.A.; Ferracuti, S.; De Giglio, O.; Caggiano, G.; Protano, C.; Valeriani, F.; Parisi, E.A.; Valerio, G.; Liguori, G.; Montagna, M.T.; Romano Spica, V.; Da Molin, G.; Orsi, G.B. \& Napoli, C. (2020). Sedentary Behaviors and Physical Activity of Italian Undergraduate Students during Lockdown at the Time of CoViD-19 Pandemic. Int. J. Environ. Res. Public Health 17, 6171. https://doi.org/10.3390/ijerph17176171

Getova, A., Mileva, E. \& Angelova-Igova, B. (2020). Online education during pandemic, according to students from two Bulgarian universities, Pedagogy, 92, 7S, 211-219.

Gobbi, E.; Maltagliati, S.; Sarrazin, P.; di Fronso, S.; Colangelo, A.; Cheval, B.; Escriva-Boulley, G.; Tessier, D.; Demirhan, G.; Erturan, G.; Yüksel, Y.; Papaioannou, A.; Bertollo, M. \& Carraro (2020). A. Promoting Physical Activity during School Closures Imposed by the First Wave of the COVID-19 Pandemic: Physical Education Teachers' Behaviors in France, Italy and Turkey. Int. J. Environ. Res. Public Health 17 (9431). https://doi.org/10.3390/ijerph17249431. 
Ivanova, V. \& Mileva, E. (2019). Teachers' satisfaction with their professional activities in physical education and sport. In P. Hájek, \& O. Vít (Ed.), Vol 7 (2019): CBU International Conference Proceedings 2019: CBU Research Institute. https://doi.org/10.12955/cbup.v7.1400,_453-458.

Hristakieva, T. (2020). Kinezitherapy Students' Attitude to Foreign Language Learning in Pandemic Conditions. Pedagogy, 92, 7S, 252-259.

Naydenova, K. \& Chernev, K. (2020). Distance learning in the conditions of COVID-19, the point of view of students and pupils. Pedagogy, 92, 7S, 260-267.

Sabev, A. (2021). Alternativni uroci po fizichesko vaspitanie i sport. [Alternative lessons in physical education and sport]. Retrieved, March 29, 2021, https://www.suivanvazov.com/alternativni-urotsi-po-fizichesko-vazpitanie-i-sport/

Savcheva, E. \& Domuschieva-Rogleva, G. (2020). Teaching challenges in sports education during the pandemic COVID-19. Pedagogy, 92, 7S, 184-194.

Sivevska, D. \& Popeska, B. (2020). Oppinions of students for their sport activity during COVID-19 pandemic - Teaching Faculty in Stip. Pedagogy, 92, 7S, 220-231.

Tejedor, S.; Cervi, L.; Pérez-Escoda, A.\& Jumbo, F.T. (2020). Digital Literacy and Higher Education during COVID-19 Lockdown: Spain, Italy, and Ecuador. Publications, 8, 48. https://doi.org/10.3390/publications8040048

Natsionalna elektronna biblioteka na uchitelite. [National electronic library of teachers]. Retrieved, March 13, 2021, from https://e-learn.mon.bg/public/study-resources/

Natsionalna strategiya za razwitie na pedagogicheskite kadri v Bulgaria (2014). [National strategy for development of the pedagogical staff in Bulgaria]. Retrieved, March 13, 2021, from https://www.mon.bg

Naredba 15 ot 22.07.2019 za statuta i profesionalnoto razvitie na uchitelite, direktorite i drugite pedagogicheski spezialisti (2016). [Regulation № 15 (from 22 July 2019) for status and professional education development of teachers, principals and other pedagogical specialists]. Retrieved, February 13, 2020, from https://www.mon.bg 